\title{
Adding a design perspective to study learning environments in higher professional education
}

\author{
Ilya Zitter • Elly De Bruijn • P. Robert Jan Simons • \\ Th. J. Ten Cate
}

Published online: 1 May 2010

(C) The Author(s) 2010. This article is published with open access at Springerlink.com

\begin{abstract}
How to design learning environments leading to learning-, thinking, collaboration- and regulation skills which can be applied to transferable, knowledge oriented learning outcomes is still controversial. We studied the designs of learning environments in innovative higher professional education more closely. To characterize learning environments we identify designable elements and position them on a scale ranging from specified, to emergent elements. Next, the main problems with the designs are identified. We introduce adaptive elements as a potential solution. We observed participants adapting such elements to suit their own needs or the needs of others. The designable and adaptive elements fulfill a dual function: they should offer contextual clues that would be available in professional practice and scaffold learners in need of support.
\end{abstract}

Keywords Higher professional education - Innovative higher education · Learning environments · Design perspective · Case studies

\section{Zitter $(\bowtie)$}

National Centre of Expertise in Vocational Education \& Training [ecbo], Utrecht, The Netherlands e-mail: ilya.zitter@ecbo.nl

E. De Bruijn

Research group Vocational Education, Faculty of Education, Hogeschool Utrecht University of Applied Sciences, Utrecht, The Netherlands

E. De Bruijn

Langeveld Institute for the Study of Education and Development in Childhood and Adolescence, Faculty of Social and Behavioural Sciences, Utrecht University, Utrecht, The Netherlands

P. R. J. Simons

IVLOS Institute of Education, Utrecht University, Utrecht, The Netherlands

P. R. J. Simons

Netherlands School of Educational Management (NSO), Amsterdam, The Netherlands

Th. J. Ten Cate

Centre of Research and Development of Education, University Medical Centre Utrecht, Utrecht, The Netherlands 


\section{Introduction}

Established roles, resources and locations of learning are extended, changed and replaced in current higher education. The rapidly changing knowledge-based economy puts pressure on higher education to extend, change and replace established roles, resources and locations of learning and deliver flexible, employable, high qualified professionals. Tynjälä et al. (2003) indicate that the massification and diversification of the higher education system, economic globalization, novel modes of knowledge production, new professional requirements and the establishment of new vocational higher education systems in many countries have challenged higher education to develop new forms of collaboration with working life. They state that learning environments in which learners work collaboratively on actual (or simulated) real-life problems are good examples of forms of collaboration between education and working life.

As a consequence of the changing relationship between higher education and working life, we, as a society of politicians, parents, teachers and company representatives, strive for new learning outcomes (Simons et al. 2000) that can be characterized as durable, flexible, functional, meaningful, generalizable and application-oriented. These characteristics relate to the transferability of more knowledge oriented learning outcomes, besides, there is also need for learning-, thinking-, collaboration- and regulation-skills that can be applied on such transferable knowledge and the process of learning.

How to design learning environments leading to these learning outcomes is still controversial. Cognitive apprenticeship (Brown et al. 1989), situated learning and legitimate peripheral participation (Lave and Wenger 1991) are approaches attempting to break the encapsulation of school learning in different ways (Engeström 1991). Kirschner et al. (2006) state that current literature offers recommendations that most experienced educators find almost impossible to implement or are reluctant to implement because they require learners to engage in activities that are highly unlikely to result in effective learning outcomes. This triggered us to study the designs of higher professional education more closely from a design perspective. The following main research question will be addressed in this article: How can we characterize learning environments in innovative higher professional education from a design perspective?

The following definition of a learning environment will be used: (1) the physical setting in which a learner or community of learners carry out their work, including all the tools, documents and other artifacts to be found in that setting and (2) the physical setting but also the social/cultural setting for such work (JCALT 2001). Designs of learning environments will be studied when they are enacted in the context of innovative, higher professional education in the process of changing its current educational practice. We will study the problems with the design in use as well. The results will be used to identify a potential design solution for the problems that occurred.

\section{Problem definition}

\section{Dichotomies in current educational research}

To characterize learning environments many dichotomies have been introduced. On a conceptual level a distinction can be made between the acquisition and the participation metaphor (Sfard 1998). In the acquisition metaphor, knowledge is considered as a commodity that can be acquired, applied, transferred and shared with others. The participation 
metaphor characterizes learning as becoming a member of a professional community. A second dichotomy refers to the definition and acquisition of knowledge in relation to professional competence. On the one hand knowledge is defined as formal knowledge that can be identified as separate from skills and attitudes. On the other, knowledge is seen as an inherent component of competence (Billet 2001a, b).

The two previous dichotomies relate to theoretical perspectives on learning, knowing and expertise, a third dichotomy has to do with the design of learning environments. On the one end there is an accent on encapsulated, school learning and on the other, on open learning approaches, such as, learning by expanding (Engeström 1991). A fourth dichotomy relates to teaching methods. Kirschner et al. (2002) identify the traditional cognitivist paradigm in which curricula are subject matter oriented, versus competency based learning based on situated cognition in (electronic) learning environments that more or less mimic real world contexts. This last dichotomy concerns the amount of instructional guidance offered to students. On one end of this distinction, there is direct instructional guidance, defined as providing information that fully explains the concepts and procedures that students are required to learn as well as learning strategy support that is compatible with human cognitive architecture. On the other side, is the minimal guidance approach which foster learning by challenging students to solve "authentic" problems or acquire complex knowledge in information-rich settings and in which minimal support is offered (Kirschner et al. 2006).

Operational framework and research questions

Most teachers and designers are struggling with the current paradigm shift from knowledge oriented teaching to more innovative, competence based learning and there is surprisingly little knowledge about designing (Kirschner et al. 2002).

Complementary to the abovementioned dichotomies we introduce a dichotomy with respect to the specificity of a design of a learning environment. This dichotomy is related to the amount of guidance dichotomy, but should have a better fit with a design perspective. It also takes account of the concept of 'friction' (Vermunt and Verloop 1999) into account, which refers to the interplay between teacher- and student-regulations of learning processes. We take the concept of design broadly, including all elements as specified in the curriculum documents and/or material (Van den Akker 1999). Designs of learning environments can be specified by educators or they can be less specified and be left emergent. The emergent elements of a design will gradually emerge in the course of joint interaction during learning activities. As basic parts of the designs of learning environments we distinguish the spaces in which learning activities will take place, the things or artifacts that play a role in the activities and the learning activities that are planned and organized. For conceptual clarity, the learning activities that are planned and organized are named 'events'. The spaces, artifacts and events can be characterized as designable elements. These elements can be specified in advance or left emergent to develop in-action gradually. Learning environments have to be designed in such a way that they lead to the intended learning activities. The main goal of these activities is to lead to the intended learning outcomes, which we defined as transferable knowledge oriented learning outcomes and the learning-, thinking-, collaboration- and regulation-skills that can be applied to such transferable knowledge and the process of learning (Simons et al. 2000).

To overcome the duality inherently related to dichotomies, Simons (1999) suggests to look for dimensions and degrees instead of dichotomies. Following this suggestion, the distinction between specified and emergent can be positioned on either side of a scale (see Fig. 1). The 


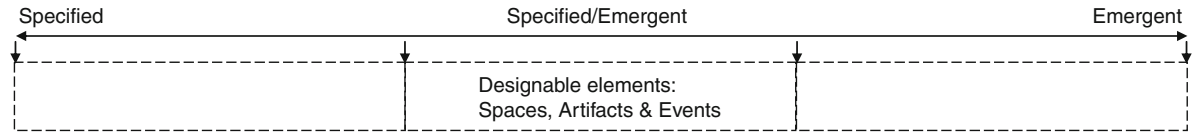

Fig. 1 Operational framework

resulting operational framework consists of designable elements as specified in the curriculum documents and/or material (Van den Akker 1999), defined above as spaces, artifacts and events. These elements can be positioned on a scale, ranging from specified elements to emergent elements.

The framework will be used to characterize the designs of learning environments in innovative, higher professional education. Next, these designs are studied in-action. While in-action, the use of specified elements and the development of emergent elements can be studied. Besides, the problems with the use of specified elements and the gradual materialization of emergent elements are examined. Furthermore, we discuss a potential design solution for the identified problems. The main research question consists of the following sub-questions:

- How can we characterize the designs of learning environments in innovative, higher professional education, consisting of spaces, artifacts and events, on a scale with on the one end of the scale 'specified' and on the other end 'emergent' ?

- What problems can be identified during the use of specified elements and the development of emergent elements when a learning environment is in-action?

- Which potential design solution can be created to address the identified problems?

\section{Structure of the article}

The remainder of this article is structured as followed. In the method-section, the selected case study method is discussed. The next section describes the collected data and the data analysis. We present the results, consisting of a list of designable elements with which the studied learning environments are characterized. Next, the results from the designs in use, including the problems with using these designs, are presented. The identified problems are presented in terms of their relations with the designable elements. Besides, we present three sub-cases describing a potential design solution. The article concludes with the discussion-section.

\section{Method}

\section{Case studies}

To answer the research questions we carried out three in-depth case studies. The strength of the case study method is its ability to examine, in-depth, a "case" within its "real-life" context (Yin 2005). This method was selected to study the designs of learning environments in-action within their real-life contexts. Both the designs themselves, as well as the designs in-action, were studied in-depth. While a design could be studied separately from its context, a design in-action can only be studied when it is enacted in its real-life context.

The case studies were carried out in three different educational contexts. In each context, one learning environment was studied. The three learning environments were 
situated in one educational institute. The educational institute is a Dutch University of Applied Sciences with about 35,000 students. The institute consists of six independent faculties. To select suitable cases, in each context, preliminary meetings were held with coordinators of the learning environments. During these meetings the learning environments were discussed.

Two main selection criteria were checked: (1) the level of authenticity, including the intended learning outcomes and (2) the prospective active involvement of the innovative educational context in question.

The first, decisive criterion was the level of authenticity, namely, whether the learning environment involved learners working collaboratively on actual (or simulated) real-life problems (Tynjälä et al. 2003), while also aiming for learning outcomes as mentioned before (Simons et al. 2000). This criterion was met by the selected cases. In the first case, learners worked on patient cases based on cases from real patients. In the second case learners worked on the design and development of websites for real, external clients. In the third case, learners worked on project from real, external clients in the domain of urban area development. This criterion was considered as decisive since the intended learning outcomes are considered as the most directional force of a design (see Fig. 2). Designable elements have to be designed in such a way that they lead to the intended learning activities, which in their turn should lead to the intended learning outcomes.

For the second criterion, it was confirmed that the participants of the innovative educational context in the process of changing their current educational practice (especially the educators directly involved) should potentially be willing to be actively involved in educational research from a design perspective for a prolonged period of time.

The following three case studies were selected, for an overview see Table 1 .

1. Faculty of Health care: Physiotherapy, Nursing and Speech therapy, in collaboration with an accelerated, 4-year medical program of an Academic teaching hospital (Case-1).

2. Faculty of Communication and Journalism: Digital communication (Case-2).

3. Faculty of Natural Sciences and Technology, Institute for the Built Environment. This context was open to students from other faculties and educational institutes (Case-3).

Below, short descriptions of the selected case studies are presented.

Case-1

The first case study was carried out in the medical and paramedical domain. The learning environment involved 32 students and four teachers for a period of 8 weeks. Students worked on a case of stroke-patients requiring the treatment and care of different healthcare professionals. The patient-cases were based on real patient-cases and the case material consisted of video and paper, instead of real patients. The aim of this learning environment was to learn to collaborate in an interprofessional healthcare team.

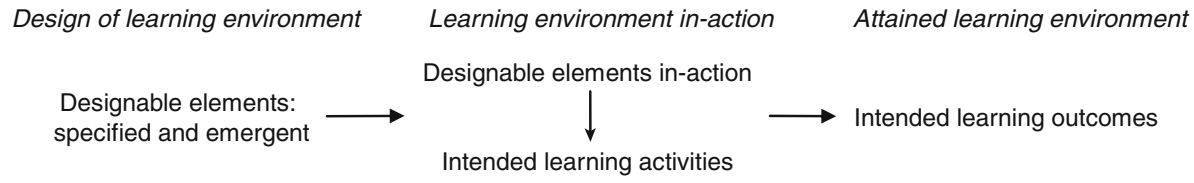

Fig. 2 Learning outcomes as main directional force 
Table 1 Overview selected case studies

\begin{tabular}{|c|c|c|c|}
\hline & Case-1 (2005) & Case-2 (2006) & Case-3 (2006/2007) \\
\hline $\begin{array}{l}\text { Faculty and } \\
\text { Study } \\
\text { program(s) }\end{array}$ & $\begin{array}{l}\text { Faculty of Health care: } \\
\text { Physiotherapy, Nursing } \\
\text { and Speech therapy. } \\
\text { Academic teaching hospital: an } \\
\text { accelerated, 4-year medical } \\
\text { program }\end{array}$ & $\begin{array}{l}\text { Faculty of } \\
\text { Communication } \\
\text { and Journalism: } \\
\text { Digital } \\
\text { communication }\end{array}$ & $\begin{array}{l}\text { Faculty of Natural Sciences and } \\
\text { Technology, Institute for the } \\
\text { Built Environment. Open to } \\
\text { students from other faculties } \\
\text { and educational institutes }\end{array}$ \\
\hline Topic & Interprofessional collaboration & System development & $\begin{array}{l}\text { Management of Urban area } \\
\text { development }\end{array}$ \\
\hline $\begin{array}{l}\text { Number of } \\
\text { students }\end{array}$ & 32 & 150 & 26 \\
\hline Duration & 8 weeks, 4 ECTS $^{\mathrm{a}}$ & 8 weeks, 14 ECTS & 6 months, 30 ECTS \\
\hline $\begin{array}{l}\text { Position in } \\
\text { overall } \\
\text { study }\end{array}$ & $\begin{array}{l}\text { Elective module for third-year } \\
\text { students of the Faculty of Health } \\
\text { care; Obligatory for first-year } \\
\text { students of medical program }\end{array}$ & $\begin{array}{l}\text { Final, obligatory } \\
\text { module for first- } \\
\text { year students }\end{array}$ & $\begin{array}{l}\text { Elective minor course for } \\
\text { third-year students }\end{array}$ \\
\hline
\end{tabular}

a European Credit Transfer and Accumulation System. The student workload of a full-time study program in Europe amounts in most cases to around 1500-1800 h per year and in those cases one credit stands for around 25-30 working hours (European Commission, Directorate-General for Education and Culture 2007)

Case-2

The second case study was carried out in the domain of digital communication. It was an obligatory learning environment for first-year students and the concluding course of their first study-year. The learning environment was set up in the form of an organization: two educators enacting the role of coordinator, twelve educators enacting the role of senior professional, and 150 students enacting the role of junior professional. The work was carried out in small project teams of three to four students. The project teams worked on the design, development and implementation of a website for external clients. The clients were from the small and medium enterprises domain or the non-profit sector. At the end, each client could select the website s/he considered the best. On request, the selected project team would implement the website and put it online.

\section{Case-3}

The third case was carried out in the domain of urban area development. There were 26 students involved, four project coaches and four external clients. There were four projects, with four different types of urban development problems in the Dutch area. The projects were globally defined by the project coaches and the external clients beforehand. Each project consisted of six to seven positions, for example, project leader, domain-expert and designer. At the start, students were required to formally apply for a position in a project, by sending an application letter and their resume. On the basis of these applications the project coaches made the formation of the project teams.

\section{Subjects}

Subjects were the learners participating in the selected learning environments. They were mainly been studied from a group-perspective and not from the perspective of a single, 
individual learner. The focus was on how the respondents handled the designable elements in-action. In each of the cases the spaces, artifacts and events for the whole group of participating learners were studied. In each of the cases, the whole group was divided in sub-groups. The observations, which are described below, were focused on one sub-group.

\section{Data collection}

To study the specified, designable elements all the educational material was collected. This material consisted of both the material designed in advance and the material that was added in-action. To study the designs in-action, observations were carried out. The face-to-face activities organized for students in each studied learning environment were observed. During the observations, extensive field notes and photos or screenshots ${ }^{1}$ were taken. The observations were focused on studying the specified, designable elements in-use. The field notes were used to describe the events, while the photos and screenshots were taken to systematically collect data about the spaces and the artifacts. The trustworthiness of these observations was increased by the use of prolonged engagement and persistent observation (Guba 1981). All organized face-to-face events were observed and the interaction in the accompanying digital learning environments was monitored. In Case- 1 and Case- 2 these observations took place for a period of 8 weeks, in Case- 3 for a period of 6 months. These data were used to answer the first sub-question of how to characterize the designs of learning environments in innovative higher professional education.

Evaluation questionnaires were used to triangulate (Guba 1981) the above types of data. These questionnaires were not made specifically for the purpose of this research, but were part of the standard evaluation procedure of the educational institute in question. A similar evaluation questionnaire was distributed to all participating students in each case. The response to the questionnaire was as followed: Case-1: $94 \%$; Case-2: $21 \%$ for the whole group, $62.5 \%$ for the observed sub-group, and Case-3: 100\%. The answers to the final open question of the questionnaires were used to study the learning experiences. These data were used to answer the second sub-question of identifying the main problems with the designs of learning environments in-action.

For each participating educational context, an evaluation report was made on the basis of a global analysis of the above data. The evaluation reports included recommendations to solve the identified problems. These evaluation reports were discussed with peers, both educational researchers and educational experts, as a form of peer debriefing (Guba 1981). They were also discussed with participants of the educational contexts with a coordinative role, as a form of member check (Guba 1981). These data were used to answer the third sub-question of finding a potential design solution for the identified problems.

\section{Data analysis}

First, the designable elements were identified by globally analyzing the three cases. The identified designable elements were used as a coding scheme for analysis of each case. The designable elements of each case were identified and the level of specificity/emergence was determined. Next, to identify the main problems, the data from the questionnaires were used. The answers to the open questions were categorized to identify the main problems across the three cases.

\footnotetext{
${ }^{1}$ Screenshot: a picture taken of a computer-screen and saved as a photo-file.
} 
The analyses so far produced a specific characteristic of designable elements, namely, adaptivity. Adaptive designable elements can be adapted by teachers, external participants and learners while a learning environment was in-action. From each case study, one subcase was selected to showcase adaptive designable elements.

The above described data analysis process was carried out in close collaboration with an educational expert. Multiple, consecutive rounds of discussion took place, until consensus was reached. This collaboration can be considered as an intensive form of peer debriefing (Guba 1981).

\section{Results}

Identified designable elements

The selected cases were holistically analyzed to further specify the designable elements: spaces, artifacts and events. Table 2 lists and describes the designable elements. We found that the designable elements could be categorized at three levels along the continuum of specified-emergent, namely: highly specified, intermediately specified/emergent and highly emergent.

When the physical spaces were highly specified, they were available at fixed times in the schedule. Also, the educators, to suit the planned event in question, specified the positioning of the tables. In case of intermediately specified/emergent, the spaces were available at fixed times, but they were designed in such a way that they could be used as workspace for project teams in different ways. When highly emergent, a physical space was reserved for the whole duration. How this reserved space was used, emerged from the joint interaction in this space.

For the digital spaces similar distinctions were identified. From a very specific digital space used as information channel, which could not be changed by participants, to digital workspaces which were partly specified by educators (intermediate), to digital workspaces which were only made available (highly emergent).

The artifacts which functioned as resources varied from specific, detailed student material that was obligatory and had the form of a student manual, a reader and hand-outs. At the intermediate level, resources which facilitated the process were offered, such as, methods, guidelines, formats and software. These resources were found to be similar to resources used in professional practice. When left emergent, learners had to find their own resources. The artifacts in the form of descriptions of deliverables which were expected from learners varied from specific descriptions to generic descriptions. Highly specific were the reports, summaries and presentations requested after each activity. Intermediate were the descriptions of a professional nature, like a diagnosis or a treatment and care plan in Case-1 and a project plan, prototype and website in Case-2. The highly emergent deliverables only specified a project plan, one intermediary deliverable and the final deliverable.

The types of events varied from very specific and planned in each detail (e.g. lectures and guided group assignments), to guided project work (intermediate), to meetings on request (highly emergent). The role descriptions varied from highly specific descriptions for a role within one activity (e.g. Chair person), to roles within a project (intermediate), to functions with multiple roles (highly emergent). Highly emergent were also the roles of the external clients, which could be enacted by the client as s/he wanted. The sequence of events varied from hourly schedules (highly specific), to a weekly planning accompanied by a sequence of 
Table 2 Identified designable elements

\begin{tabular}{|c|c|c|c|}
\hline $\begin{array}{l}\text { Designable } \\
\text { element }\end{array}$ & Highly specified & $\begin{array}{l}\text { Intermediately specified/ } \\
\text { emergent }\end{array}$ & Highly emergent \\
\hline Physical spaces & $\begin{array}{l}\text { Lecture hall } \\
\text { Classroom available at set } \\
\text { times in schedule. } \\
\text { Positioning of tables } \\
\text { specified by educators }\end{array}$ & $\begin{array}{l}\text { Classroom available at set } \\
\text { times during the week to } \\
\text { be used as work space for } \\
\text { the project teams of one } \\
\text { sub-group ( } 6 \mathrm{~h} \text { in total })\end{array}$ & $\begin{array}{l}\text { Classroom reserved for the } \\
\text { duration of the learning } \\
\text { environment, to be used } \\
\text { for all types of activities } \\
\text { (6 months) }\end{array}$ \\
\hline Digital spaces & $\begin{array}{l}\text { Common digital space used } \\
\text { as information channel } \\
\text { (announcements, changes } \\
\text { to planning, material etc.) }\end{array}$ & $\begin{array}{l}\text { Workspace made for each } \\
\text { project team, including } \\
\text { an inbox to hand in final } \\
\text { results for assessment }\end{array}$ & Access to digital workspaces \\
\hline $\begin{array}{l}\text { Artifacts to be } \\
\text { used as } \\
\text { resources }\end{array}$ & $\begin{array}{l}\text { Specific, obligatory } \\
\text { resources: student } \\
\text { manual, reader, hand-outs }\end{array}$ & $\begin{array}{l}\text { Resources to facilitate the } \\
\text { process: methods, formats, } \\
\text { guidelines and software }\end{array}$ & $\begin{array}{l}\text { Suitable resources have to } \\
\text { be selected by learners }\end{array}$ \\
\hline $\begin{array}{l}\text { Artifacts : } \\
\text { descriptions of } \\
\text { (intermediary) } \\
\text { deliverables }\end{array}$ & $\begin{array}{l}\text { Specific descriptions of } \\
\text { deliverables of all } \\
\text { activities: reports, } \\
\text { summaries, presentations }\end{array}$ & $\begin{array}{l}\text { Descriptions of deliverables } \\
\text { of a professional nature: } \\
\text { diagnosis, treatment and } \\
\text { care plan; } \\
\text { Project plan, designs, } \\
\text { prototype, website }\end{array}$ & $\begin{array}{l}\text { Generic deliverables: } \\
\text { project plan, intermediary } \\
\text { result and final result. }\end{array}$ \\
\hline $\begin{array}{l}\text { Different types } \\
\text { of events }\end{array}$ & $\begin{array}{l}\text { Lectures } \\
\text { Self-study assignments } \\
\text { Guided group assignments } \\
\text { Presentations by learners }\end{array}$ & $\begin{array}{l}\text { Project work guided by } \\
\text { educator in role of senior } \\
\text { professional and expert. } \\
\text { Meetings with external } \\
\text { clients planned by } \\
\text { educators. } \\
\text { Visits to workplaces of } \\
\text { external professionals }\end{array}$ & $\begin{array}{l}\text { Unguided project work } \\
\text { Meetings on request with } \\
\text { project coach. } \\
\text { Meetings on request with } \\
\text { external client. }\end{array}$ \\
\hline $\begin{array}{l}\text { Role } \\
\text { descriptions }\end{array}$ & $\begin{array}{l}\text { Specific instructions for } \\
\text { role in activity (e.g. Chair } \\
\text { person) }\end{array}$ & $\begin{array}{l}\text { Descriptions of roles in a } \\
\text { project, like project leader, } \\
\text { functional designer and } \\
\text { graphical designer }\end{array}$ & $\begin{array}{l}\text { Descriptions of functions } \\
\text { with multiple roles in a } \\
\text { project. } \\
\text { No strict role description for } \\
\text { the external client }\end{array}$ \\
\hline $\begin{array}{l}\text { Sequence of } \\
\text { events }\end{array}$ & $\begin{array}{l}\text { Weekly and hourly } \\
\text { planning of events. } \\
\text { Breaks and sequence within } \\
\text { events specified as well }\end{array}$ & $\begin{array}{l}\text { Weekly schedule of } 1 \\
\text { lecture and } 6 \text { h of guided } \\
\text { project work. } \\
\text { Project divided into } 2 \\
\text { phases. } \\
\text { Sequence of deliverables } \\
\text { was specified }\end{array}$ & $\begin{array}{l}\text { Global sequence of project: } \\
\text { project plan, intermediary } \\
\text { result and final result. } \\
\text { Global sequence of types of } \\
\text { events: presentation of } \\
\text { intermediary/final result to } \\
\text { client followed by a } \\
\text { review by a panel of } \\
\text { experts }\end{array}$ \\
\hline
\end{tabular}

deliverables covering 8 weeks (intermediate), to a global sequence covering 6 months (highly emergent).

\section{Cross-case comparison of the designs}

The listed designable elements at three levels of specificity/emergence were used to compare the designs of the three learning environments studied. The differences between the levels of specificity/emergence are that highly specified designable elements were specified at a micro-level, intermediate elements were specified globally and highly 
emergent elements were specified generically. As such, a learning environment can also be seen in terms of granularity. The highly specified learning environment was finegrained, while the highly emergent learning environment was coarse-grained. In Table 3 an overview is presented of the levels of specificity/emergence and the overall granularity of the learning environments studied. Case-1 consists mainly of highly specified elements that are specified at micro-level. Case-2 consists of globally specified elements at an intermediate level of specificity/emergence. Case- 3 consists of generic and highly emergent elements.

\section{Identification of the main problems}

Next, the designs of the learning environments were studied in use. The problems which occur when using the designable elements are identified. They are described in terms of their relation with the designable elements.

The students experienced the specified, fine-grained elements of the learning environment of Case-1 as 'tedious', 'too slow', 'repetitious' and 'not challenging enough'.

The observations showed that learners did not extensively use domain-specific resources about stroke-patients during the various activities. In the questionnaires, they complained about the lack of attention to domain-specific knowledge in the learning environment. The learners did not seem to realize that the domain-specific resources were left highly emergent, which was in sharp contrast with the highly specified other elements of the learning environment. Two events that were also left more emergent, namely, the two interprofessional meetings similar to professional practice, were experienced as highly valuable: 'Eventually, I learned a lot from the interprofessional meetings'; 'more interprofessional meetings!'.

In Case-2, the learners experienced working for a real, external client of which his/her role was left highly emergent, as very positive: 'It was great to work for a real client'; 'It made us feel a lot more responsible for the results we had to deliver'. There are also negative experiences with the external client, since students experience a lack of feedback. 'There is too little feedback from the external client, and it is much too slow'. 'The external client should have been screened better at the start, to avoid that he changes his mind during the course'. As in Case-1, the more specific elements of the learning environment contrasted with the elements which were left emergent. The sequence of events and the (intermediary) deliverables were specified on a weekly basis. Slow feedback and a client changing his/her mind, did not align with the stricter sequence of events and deliverables.

Another problem experienced in Case- 2 was related to the technical complexity. The learners were allowed to determine the level of technical complexity of the website they were expected to deliver, this aspect was left emergent. At the same time, it was specified that the external client was to pick the best website to go online. As a result, learners did not seem to want to lower the level of technical complexity to match their capabilities, since they expected this would also lower the chances of being selected as the best project team by the client.

As in Case-1, learners were expected to find their own technical resources and study them. At the same time, a series of lectures and obligatory books were specified for them. Similar to Case-1, on the one hand, resources were specified in the form of lectures and books, while on the other hand, they were expected to find their own resources. Observations showed that learners found their way to online, technical resources about the software, but not to many other technical resources. 
Table 3 Cross-case comparison

\begin{tabular}{llll}
\hline $\begin{array}{l}\text { Designable } \\
\text { element }\end{array}$ & Highly specified & $\begin{array}{l}\text { Intermediately } \\
\text { specified/emergent }\end{array}$ & Highly emergent \\
\hline
\end{tabular}

Physical spaces

Case-1

$$
\begin{aligned}
& \text { All classrooms } \\
& + \text { positioning of } \\
& \text { tables specified }
\end{aligned}
$$

Case-2

Classroom available

as workspace for

project teams

\section{Case-3}

Digital spaces

Information channel
which cannot be
changed

Case-2

Case-3

Artifacts to be used as resources

Case-1

Case-2

Case-3

Artifacts : descriptions of (intermediary) deliverables
Methods, formats, guidelines

Methods, formats, guidelines and software
Classroom reserved for 6 months for all activities

Common spaces to be used by learners

Workspaces for project teams, partly specified

Workspaces available

Select own domain-specific resources

Select own resources

$\begin{array}{ll}\text { Case-1 } & \begin{array}{l}\text { Specific descriptions } \\ \text { of deliverables } \\ \text { (reports, summaries, } \\ \text { presentations) }\end{array}\end{array}$

Case-2

Case-3

Different types of events

$\begin{array}{ll}\text { Case-1 } & \text { Lectures, self-study } \\ \text { assignments, guided } \\ \text { group assignments, } \\ \text { presentations }\end{array}$

Case-2

Case-3

Role descriptions
Case-1
Specific instructions
for role within an activity

Case-2
Global descriptions
of deliverables of
professional nature

Two events similar to professional practice

Guided project work Planned meetings with external client

Meetings on request with project coach and external client

No strict role description for the external client 
Table 3 continued

\begin{tabular}{|c|c|c|c|}
\hline $\begin{array}{l}\text { Designable } \\
\text { element }\end{array}$ & Highly specified & $\begin{array}{l}\text { Intermediately } \\
\text { specified/emergent }\end{array}$ & Highly emergent \\
\hline Case-3 & & & $\begin{array}{l}\text { Descriptions of functions with } \\
\text { multiple roles } \\
\text { No strict role description for the } \\
\text { external client }\end{array}$ \\
\hline \multicolumn{4}{|c|}{ Sequence of events } \\
\hline Case-1 & $\begin{array}{l}\text { Weekly and hourly } \\
\text { schedule }\end{array}$ & & \\
\hline Case-2 & & $\begin{array}{l}\text { Weekly schedule } \\
\text { Sequence of } \\
\text { deliverables }\end{array}$ & \\
\hline Case-3 & & & Global sequence of 6 months \\
\hline \multicolumn{4}{|l|}{ Granularity } \\
\hline Case-1 & $\begin{array}{l}\text { Fine-grained } \\
\text { Specified at micro- } \\
\quad \text { level }\end{array}$ & & \\
\hline Case-2 & & $\begin{array}{l}\text { Medium-grained } \\
\text { Globally specified }\end{array}$ & \\
\hline Case-3 & & & $\begin{array}{l}\text { Coarse-grained } \\
\text { Generically specified }\end{array}$ \\
\hline
\end{tabular}

In comparison to the other cases, most elements were left emergent in Case-3. The learners complained about the vagueness and bad planning. The learners were expected to specify their own weekly schedule and physical and digital workspaces. They were also expected to specify a sequence of deliverables and the professional methods and instruments they would use. In Case-3, the learners felt most overwhelmed. Not all the project teams made arrangements for a schedule or their workspaces, adding to the overall experience of vagueness and bad planning. In comparison to the other teams, one of the project teams developed emergent elements in joint interaction more purposely. In this team, it was made specific where to work (physical spaces) and the team made extensive use of $\mathrm{Gmail}^{2}$ as supporting digital workspace. Besides, they made a specific weekly schedule and an overall project plan with a sequence of activities, intermediary deliverables and a choice for domain-specific methods.

The other major problem experienced by most of the learners was the mismatch between what they expected they could learn and the projects which were globally specified in advance by the educators: 'There should be enough work for every project member'; 'The project should be screened better or less architects/designers should be admitted!'; 'The projects should have a better match with the functions that were on offer'. They did not seem to realize they were expected to organize additional workshops and lectures when needed, as this aspect was left emergent. They also did not seem to realize that they could change the specifications of the project, which was only globally specified in advance, to suit their own learning goals. In Case-3, the elements left highly emergent were broad and extensive. Though they did specify many aspects themselves, specifying the boundaries of project itself seemed like a step too far for many learners.

\footnotetext{
${ }^{2}$ Gmail: an online e-mail facility. For more information, see www.gmail.com.
} 
In Case- 1 and Case- 2 the identified problems were related to the contrast between highly specified and more emergent elements. Observations showed that the learners do not develop the emergent elements. The experiential data showed that the learners have negative experiences with emergent elements. At the same time, in Case-1 learners complained about the highly specific elements. Alternatively, in Case- 3 all the elements were left highly emergent. Observations showed that learners did not develop the necessary emergent elements and the experiential data confirmed that the learners experienced problems. We will now turn to a potential design solution for the identified problems.

Adaptive designable elements

During the data analysis we found a specific characteristic of designable elements: adaptivity. Analysis showed that some elements could be adapted by participants when a learning environment was in-action. Educators, learners, senior learners and external participants were observed to adapt designable elements. The adaptive elements were not specified in advance by educators, but were specified by participants to suit the situation while in-action. They also differed from emergent elements, which would gradually emerge from the joint interaction during learning activities. Participants adapted designable elements by specifying them for their own use or for the use of others. The next three sub-sections will present the selected sub-cases showcasing adaptive designable elements.

Case-1: adaptive artifacts

Case- 1 took place in the Healthcare domain. To support communication and collaboration between different healthcare professions, a common framework has been developed for the diagnosis, treatment and care of patients from multiple perspectives. This framework can be translated into a visual representation, a feature that is of benefit in educational contexts (Allan et al. 2006). The framework was used as one of the fundaments for the learning environment. Observations showed that when a teacher noticed that the students had difficulty with the analysis of a patient case, she drew the visual representation of the common framework on the whiteboard. In interaction with the students, the patient case was ordered according to the framework. Other observations showed students using the visual representation to summarize patient cases, to exchange these and to give each other feedback, when one student turned out to be more knowledgeable than another. Furthermore, students found resources about the framework online, using the Web to complement resources offered in the learning environment.

By introducing artifacts from professional practice with different representations, both educators and learners were able to adapt the artifacts to suit the situation.

\section{Case-2: adaptive use of physical space}

The learning environment of Case- 2 was relatively large scale and involved 150 students. To feasibly accommodate this large number of students, the learning environment was positioned at the physical location of the educational institute. There were six sub-groups, for each sub-group, a regular classroom was available as workspace for a fulltime working week. At scheduled times, $6 \mathrm{~h}$ each week, a duo of teachers was present in the workspace. The sub-groups, consisting of about seven project-teams worked side by side in 
classrooms. Students helped each other and showed each other intermediary results. There was also a senior student, fulfilling the role of account manager (liaison between the project teams and the external client). Students also requested advice and feedback from the senior student. When the teachers were present, students could request help or show intermediary results to receive feedback. Besides, the teachers also walked around, offering their advice without a direct request.

By having a physical space available according to a weekly schedule, with access to educators, a senior peer, peers and team members, the participants were able to adapt their workspace and support to suit the situation.

\section{Case-3: adaptive event with external participants}

In Case-3, students worked more independently than in the other two cases. This independence was caused by the differences in projects. In Case-1 students worked on the same patient cases, in Case-2 students worked on similar projects, while in Case-3 the students worked on very different projects. To help students improve the quality of the (intermediary) results, students were required to present their intermediary and semi-final results to a panel of practitioners/experts three times. During these sessions, students received feedback on how to improve their results. The content of the activity could be adjusted to suit the needs of students. The panel, consisting of external participants, offered more structure and guidance where needed, while for other project teams, the feedback closely resembled feedback as given in professional practice.

By planning the above event and organize it as described above, the external participants were able to adapt their feedback to suit the situation.

In the above three sub-cases three adaptive, designable elements have been showcased. These adaptive elements differed from both the specified and the more emergent elements. The specified elements were specified in advance and were to be used as specified. The more emergent elements were to be jointly developed during interaction. The adaptive elements were left open to be specified by all participants, educators, learners and external participants when needed. An individual learner could specify them or they could be specified for a group of learners. Besides, how specific the designable element in question were to be made, could be determined in-action and could therefore be adapted to suit the situation.

\section{Discussion}

In this article, a design perspective is taken to characterize learning environments in innovative, higher professional education. To help characterize learning environments, dichotomies in current educational research are explored. To complement these dichotomies, we provide an additional focus from a design perspective: the level of specificity of the designable elements of a learning environment. To this effect, we introduce a scale with on one end 'specified' and on the other end 'emergent' allowing the positioning of designable elements. This operational framework can be used to characterize the designs of learning environments and identify the main problems of design in-action.

As a potential design solution, adaptive elements are introduced, as we observed that participants adapted designable elements by specifying them for their own use or for the use of others when suitable. 
The designable elements as introduced in this article can be related to the concept of 'scaffolds'. The original use of scaffolding described interactions between a parent and a child or a tutor and a student in which the parent or tutor offers support. Since then, 'scaffolding is no longer restricted to interaction between individuals - artifacts, resources, and environments themselves are also being used as scaffolds' (Puntambekar and Hübscher 2005). Puntambekar and Hübscher state that there are two main facets of the current construct of 'scaffolding'. Firstly, the current construct is enriched with techniques of providing support. Secondly, they state that current implementations of scaffolding lack an emphasis of necessary process-aspects, such as, the process of continuous diagnosis of the need for support and the process of fading of scaffolding when suitable are replaced by more permanent and unchanging support. The lack of emphasis on process-aspects is also recognizable for the designable elements we introduced: either they are specified by the educators or they are left more emergent. The adaptive elements do provide means for more emphasis on process-aspects. They can be designed in such a way that participants, educators, external participants senior learners and learners, should be able to continuously diagnose whether support is needed. If this is the case, the element can be specified for single or multiple learners, not only by educators, but also by other participants.

Additionally, an important function of the designable and adaptive elements is to help contextualize a learning environment. Learners are expected to work on deliverables in physical and digital spaces situated in educational institutes. When they would work in a professional context, the spaces, artifacts and events in that context would provide contextual clues of how to proceed. In an educational context, these clues need to be specified by educators when needed. Designable and adaptive elements can be designed to fulfill a dual function: they should offer contextual clues that would be available in professional practice and scaffold learners if they need support.

In relation to the amount of guidance dichotomy of Kirschner et al. (2006), we claim here that a well-designed learning environment can provide suitable and sufficient guidance without retreating to strictly traditional methods of direct instruction or being forced to offer minimal guidance, which is not always suitable. However, it is a major challenge to do so, since the implementation of innovative approaches is not a linear process and involves tackling a great many problems (Windschitl 2002). The results of this study might be helpful in this process.

The results presented in this article are the result of in-depth, qualitative research. Future research will be carried out to study the effectiveness of the adaptive elements introduced here. Future research will also include studying how to systematically improve the design of learning environments in innovative, higher professional education.

Acknowledgments The research presented in this article was carried out in close collaboration with all the participants (students, teachers, external participants and coordinators) of the studied educational contexts. The authors would specifically like to acknowledge the following participants (in alphabetical order). Case-1: Gerda Croiset, Ineke Lam, Evelijn Raven, Wilfred Rubens, Eric Stutterheim, Angela Tuyp, Anne Visser, Tineke Westerveld and Harriët Wittink. Case-2: Hussam Hadi, Guus Koning and Pim Schonk. Case-3: Debby Goedknegt, Mirjam Huffstad, Ellen van Keeken, Marius Kiers, Peter Martens, Bas Ouwehand, Rien van Stigt and Frank Stiksma.

Open Access This article is distributed under the terms of the Creative Commons Attribution Noncommercial License which permits any noncommercial use, distribution, and reproduction in any medium, provided the original author(s) and source are credited. 


\section{References}

Allan, C., Campbell, W., Guptill, C., Stephenson, F., \& Campbell, K. (2006). A conceptual model for interprofessional education: The international classification of functioning, disability and health (ICF). Journal of Interprofessional Care, 20(3), 235-245.

Billett, S. (2001a). Knowing in practice: Re-conceptualising vocational expertise. Learning and Instruction, $11,431-452$.

Billett, S. (2001b). Vocational educators: Understanding practice at work. In C. Velde (Ed.), International perspectives on competence in the workplace. Research, policy and practice (pp. 41-65). Dordrecht: Kluwer.

Brown, J. S., Collins, A., \& Duguid, P. (1989). Situated cognition and the culture of learning. Educational Researcher, 18(1), 32.

Engeström, Y. (1991). Non scolae sed vitae discimus: Toward overcoming the encapsulation of school learning. Learning and Instruction, 1(3), 243-259.

European Commission, Directorate-General for Education and Culture. (2007). ECTS key features. Retrieved 1st of April 2009 from http://ec.europa.eu/education/lifelong-learning-policy/doc/ectskey_en.pdf.

Guba, E. G. (1981). Criteria for assessing the trustworthiness of naturalistic inquiries. Educational Technology Research and Development, 29(2), 75-91.

JCALT. (2001). Effective networked learning in higher education: Notes and guidelines. Deliverable 9, Vol. 3 of the final report to JCALT (Networked Learning in Higher Education Project). Retrieved 30 June 2008, from http://csalt.lancs.ac.uk/jisc/docs/guidelines_final.doc.

Kirschner, P. A., Carr, C., Van Merriënboer, J., \& Sloep, P. (2002). How expert designers design. Performance Improvement Quarterly, 15(4), 86-104.

Kirschner, P. A., Sweller, J., \& Clark, R. E. (2006). Why minimal guidance during instruction does not work: An analysis of the failure of constructivist, discovery, problem-based, experiential, and inquirybased teaching. Educational Psychologist, 41(2), 75-86.

Lave, J., \& Wenger, E. (1991). Situated learning: Legitimate peripheral participation. Cambridge University Press.

Puntambekar, S., \& Hübscher, R. (2005). Tools for scaffolding students in a complex learning environment: What have we gained and what have we missed? Educational Psychologist, 40(11), 1-12.

Sfard, A. (1998). On two metaphors for learning and the dangers of choosing just one. Educational Researcher, 27(2), 4-13.

Simons, P. R. J. (1999). Transfer of learning: Paradoxes for learners. International Journal of Educational Research, 31(7), 577-589.

Simons, P. R. J., Van der Linden, J., \& Duffy, T. (2000). New learning: Three ways to learn in a new balance. In P. R. J. Simons, J. Linden, \& T. van der Duffy (Eds.), New learning (pp. 1-20). Dordrecht: Kluwer.

Tynjälä, P., Välimaa, J., \& Sarja, A. (2003). Pedagogical perspectives on the relationships between higher education and working life. Higher Education, 46(2), 147-166.

Van den Akker, J. (1999). Principles and methods of development research. In J. Van den Akker, R. M. Branch, K. Gustafson, N. Nieveen, \& T. Plomp (Eds.), Design approaches and tools in education and training (pp. 1-14). Dordrecht: Kluwer.

Vermunt, J. D., \& Verloop, N. (1999). Congruence and friction between learning and teaching. Learning and Instruction, 9, 257-280.

Windschitl, M. (2002). Framing constructivism in practice as the negotiation of dilemmas: An analysis of the conceptual, pedagogical, cultural and political challenges facing teachers. Review of Educational Research, 72, 131-175.

Yin, R. K. (2005). Case study methods. In J. Green, G. Camilli, \& P. Elmore (Eds.), Complementary methods for research in education (3rd ed.). Washington, DC: American Educational Research Association. 